\title{
Processo de Segurança Contra Incêndio e Pânico no Complexo da FAET/ICET/IF, UFMT - Campus Cuiabá
}

\section{Safety Case Against Fire and Panic in Complex FAET/ICET/IF, UFMT - Campus Cuiabá}

\author{
${ }^{1}$ Augusto César de Oliveira Dias; ${ }^{2}$ Margarida Marchetto \\ 1Pós-Graduando do curso de Engenharia de Segurança do Trabalho da Faculdade de Arquitetura, e Tecnologia- \\ FAET da Universidade Federal de Mato Grosso-UFMT \\ (eng.acod@gmail.com) \\ 2Professora dos Programas de Pós-Graduação em Recursos Hídricos, Engenharia de Edificação e Ambiental e \\ Segurança do Trabalho da FAET-UFMT
}

\begin{abstract}
RESUMO: Este artigo têm a finalidade de avaliar e sugerir alterações de prevenções, combate a incêndio e pânico, no o complexo da FAET/ICET/IF, localizado no campus da UFMT, no município de Cuiabá. Sabe-se que as edificações públicas em sua maioria não atendem a todos os requisitos normativos de prevenção e combate a incêndios. Sendo esta situação não diferente nas edificações que compõem a UFMT, pois é evidente que os equipamentos e sistemas de prevenção, são aquém do necessário, os que existem não recebem manutenção, acarretando assim grande potencial para a ocorrência de um possível sinistro.

A edificação estudada possui uma construção antiga com um sistema de prevenção e combate incêndio e pânico deficiente, defasado e insuficiente quanto às necessidades normativas, que não contribuirá de forma eficaz, no caso de ocorrência de sinistros, para o alerta e evacuação da população da edificação, para o combate ao fogo e para a preservação do patrimônio existente.

Porém, recomenda-se compor equipe especializada de Bombeiros Civis para a formação da brigada de incêndio, construir saídas de emergências conforme preconizam as normas e executar os sistemas de detecção de alarme, iluminação, sinalização, hidrante e extintores de incêndio.
\end{abstract}

Palavras-chave: PSCIP; Prevenção, Segurança em Edificações.

ABSTRACT:- This article aim to evaluate and suggest changes to prevention, fire fighting and panic in the complex FAET / ICET / IF, located on the campus of UFMT in the city of Cuiabá. It is known that in public buildings mostly do not meet all the regulatory requirements of prevention and fire fighting. Being east situation no different in the buildings that make up the UFMT, it is evident that the equipment and prevention systems are insufficient, those who are not maintained, thus causing a major focus for a possible loss.

The building studied has an old building with a system to prevent and fight fire and disabled panic, outdated and insufficient regard to regulatory requirements, which do not contribute effectively in the event of claims for the alert and evacuation of the building population, to fight the fire and to preserve the existing heritage.

However it is recommended to compose specialized team of Civil Firefighters for the formation of the fire brigade, construct emergency exits as recommended standard and perform alarm detection systems, lighting, signs, fire hydrant and fire extinguishers.

Keywords: PSCIP; Prevention, Building Safety

\section{INTRODUÇÃOO}

Nas décadas de 70 e 80 ocorreram grandes incêndios em edifícios públicos no Brasil, como Conjunto Nacional (1978) e torres da CESP (1987) em São Paulo, no Edifício Itaboraí onde funcionavam o Banco do Brasil e a Cacex, e no Ministério da Habitação e Bem-Estar Social, ambos em 1988, em Brasília. Esses eventos demarcaram uma preocupação com a segurança contra incêndios nas edificações. Foram incêndios em que centenas de pessoas perderam a vida, danos materiais incalculáveis, perdas de documentos importantes e geraram uma fobia coletiva do fogo nas grandes edificações. (BENTRANO, 2007)

Sobre este assunto, é importante relatar que tragédias e acidentes desta natureza continuam acontecendo, como é o caso recente do incêndio da Boate Kiss, acontecido em janeiro de 2013, em Santa Maria/RS. Este acontecimento é a real 
prova da falta de cultura de segurança em nosso pais, seja motivado por negligência dos proprietários ou descaso dos órgãos públicos. Uma vez que, conforme o Relatório Técnico apresentado pelo Conselho Regional de Engenharia do Rio Grande do Sul (CREA/RS 2013), o incêndio ocorreu no interior de um galpão, adaptado de forma errônea para ser um bar ou danceteria. Sendo essas mudanças arquitetônicas efetuadas não levarem em consideração os possíveis riscos como também os investimentos realizados no âmbito da segurança foram mal direcionados ou insuficientes.

A cultura de proteção contra incêndio deve ser vista primeiramente como uma obrigação frente à necessidade de preservar a vida humana, e secundariamente o patrimônio envolvido, independente do seu custo financeiro. A construção de qualquer tipo de edificação segura é dever irrecusável e ético do projetista, executor da obra e do proprietário, independente das exigências legais.

Sendo mais preocupantes em edificações públicas, pois em sua maioria não atendem a todos os requisitos normativos de prevenção e combate a incêndios. Nas edificações que compõem a UFMT é evidente que os equipamentos e sistemas de prevenção, são aquém do necessário, os que existem não recebem manutenção, acarretando assim um grande foco para um possível sinistro.

Diante o exposto, este artigo têm a finalidade de avaliar e sugerir alterações de prevenções, combate a incêndio e pânico, no o complexo da FAET/ICET/IF, localizado no campus da UFMT, no município de Cuiabá.

E ainda sim, podendo contribuir com a instituição, ao informar que as suas instalações não atendem a todos os requisitos normativos de prevenção e combate a incêndios, e auxiliar na obtenção, por parte da universidade, do Alvará de Prevenção Contra Incêndio e Pânico (APCIP) do Corpo de Bombeiro
Militar do Estado de Mato Grosso (CBMMT).

\section{MATERIAIS E MÉTODOS}

Área de estudo

O complexo da FAET/ICET/IF localiza-se na Universidade Federal de Mato Grosso - Campus Cuiabá, dos quais fazem parte os departamentos dos cursos de Arquitetura e Urbanismo, Engenharia Civil, Engenharia Elétrica, Engenharia Sanitária e Ambiental, Geologia, Matemática, Física e Química, representado na Figura 1.

Figura 1:Complexo da FAET/ICET/IF

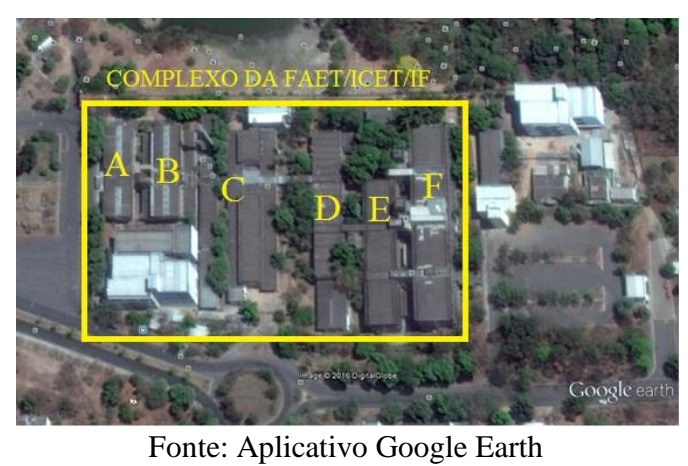

Cabe vivificar que segundo o editorial da revista E\&S Engineering (2014), no início da UFMT, os cursos das Engenharias eram vinculados ao Centro de Ciências Exatas e de Tecnologia (CCET). Em 1970 ocorreu um desdobramento e deu-se origem a Faculdade de Tecnologia e Engenharia (FTEN), posteriormente foi alterada para Faculdade de Arquitetura, Engenharia Tecnologia (FAET). Em 1968 foi iniciado o curso de Engenharia Civil, nos anos 1970, foram criados os cursos de Engenharia Elétrica e Engenharia Sanitária (posteriormente alterado para Sanitária e Ambiental). O curso de Arquitetura e Urbanismo foi criado em 1995. Atualmente a FAET é constituída por quatro cursos de graduação (Engenharia Civil, Elétrica, Sanitária e Ambiental e Arquitetura).

Em 2008, houve uma nova reestruturação no Instituto de Ciências Exatas e da Terra (ICET) e atualmente o mesmo compreende: Cursos de Pós- 
Graduação; Cursos de Graduação; Departamentos Acadêmicos; Mestrado em Geociências; Mestrado em Matemática; Mestrado em Química; Doutorado em Ciências e Matemática; Mestrado em Recursos Hídricos; Bacharelado em Estatística; Bacharelado em Geologia; Bacharelado em Química; Licenciatura Plena em Química; Licenciatura Plena em Matemática; Estatística; Geologia Geral; Matemática; Química e Recursos Minerais.

O Programa de Pós-graduação em Engenharia de Edificações e Ambiental (PPGEEA) vinculado a FAET foi criado em 2008, após discussão da comunidade acadêmica, principalmente docentes especialistas de várias áreas ressaltarem a importância do mestrado para Mato Grosso, para trabalharem e pesquisarem as problemáticas na região, no estado. $\mathrm{O}$ curso é dirigido para engenheiros, arquitetos e áreas afins, com a missão de gerar, buscar, criticar, sistematizar, difundir e transferir conhecimentos científicos, tecnológicos e culturais relacionados com as áreas de conhecimento do curso.

Diante a essa toda gama de cursos na área da ciência e tecnologia, segundo dados fornecidos pela universidade, o número de pessoas que trabalham $\mathrm{e}$ estudam no complexo da FAET/ICET/IF é de aproximadamente 3.000 pessoas.

\section{Métodos}

A primeira parte do trabalho aborda estudos de diversas revisões bibliográficas e NBR- Norma Instituição Técnica referentes ao tema de sistema de prevenção, combate a incêndio e pânico.

A segunda parte do estudo consistiu no reconhecimento do local de posse de uma planta baixa da edificação onde funciona o complexo da FAET/ICET/IF cedidos pela PROPLAN (Pró-Reitoria de Planejamento), adotando as alterações do layout, para proceder às correções do projeto, bem como os preventivos existentes.

Finalmente, foi proposto um projeto de prevenção e combate na edificação onde abriga a referida edificação, para que ofereçam segurança aos funcionários, usuários e as pesquisas ali existente.

\section{RESULTADOS E DISCUSSÃO}

Classificação da edificação em estudo

O complexo em questão é constituído por salas de aulas, administração, laboratórios e auditórios.

O complexo é dividido em seis blocos A, B, C, D, E, F e ampliações mais um almoxarifado, possui três pavimentos, somando uma área total de $19.201,08 \mathrm{~m}^{2} \mathrm{e}$ altura variada em função da quantidade de pavimentos, sendo a maior altura de $11,39 \mathrm{~m}$, medida de piso a piso, encontrada no bloco $\mathrm{F}$ o qual possui três pavimentos.

As classificações foram realizadas de acordo com as Tabelas anexas a Lei $8399 / 2005$ conforme preconiza a NTCB 01/2008 - Procedimentos administrativos.

Todos os blocos segundo a Lei 8399/2005 serão classificadas de acordo com a Quadro 01. Sendo que nos casos em que seja necessário o levantamento da carga de incêndio (NTCB 07), a tabela abaixo deverá ser preenchida:

- Grupo E - Educacional e Cultural;

- Carga de Incêndio - E-1 CNAE 8532-5/00 - Carga de Incêndio $300 \mathrm{Mj} / \mathrm{M}^{2}$. 
Dias A. C. de O.; Marchetto M. Processo de Segurança Contra Incêndio e Pânico no Complexo da FAET/ICET/IF, UFMT - Campus Cuiabá. E\&S - Engineering and Science, (2016), 5:2.

Quadro 1 - Requisitos da Legislação

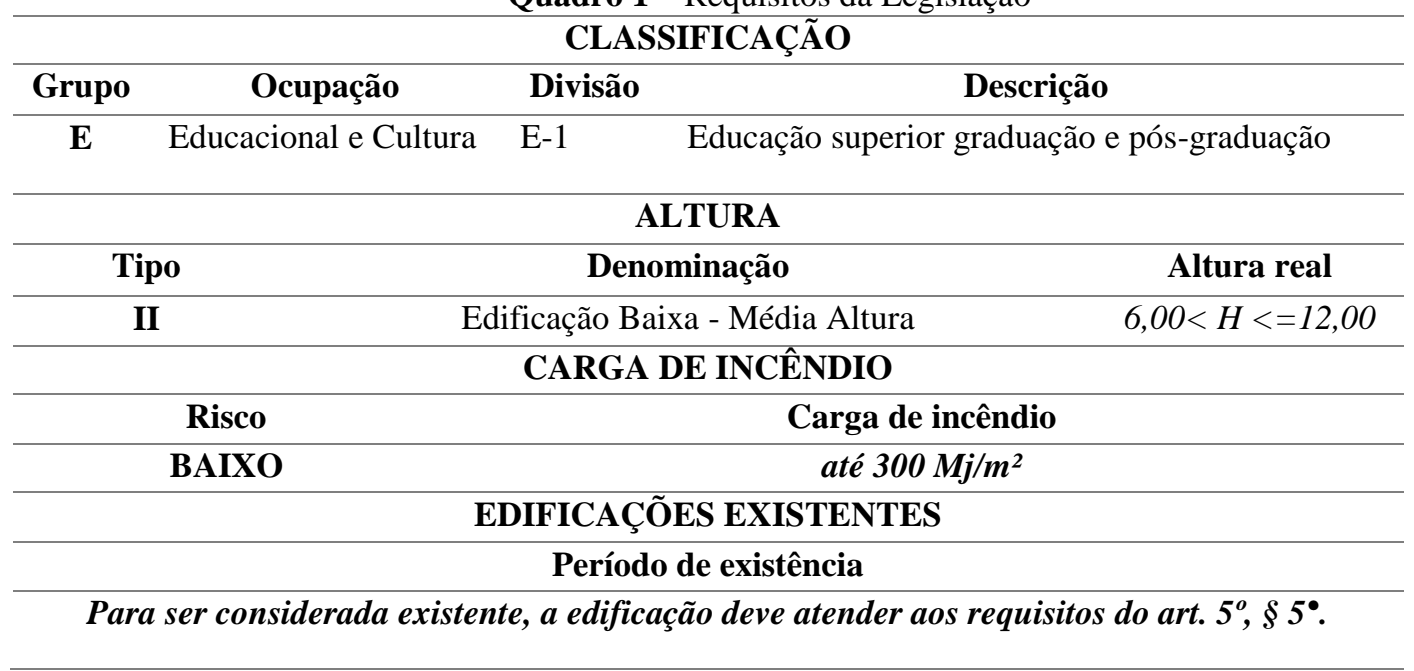

Medidas de segurança contra incêndio e pânico

As medidas de segurança abaixo descritas seguem a respectiva ordem das exigências constantes das $\mathrm{F}$, da Lei $\mathrm{n}^{\mathrm{o}}$ $8.399 / 2005$.

Acesso de viatura na edificação

Esta medida de segurança foi dimensionada atendendo a Instrução
Técnica $\mathrm{n}^{\circ}$ 06/2004 do Corpo de Bombeiros da Polícia Militar do Estado de São Paulo - Acesso de viatura na edificação, adotada pela Portaria $n^{\circ}$ 001/DSCIP/CBMMT/2011. As características da via de acesso á edificação são exibidas no Quadro 2.

Quadro 2 - Características da via de acesso á edificação.

\begin{tabular}{|c|c|c|}
\hline \multicolumn{3}{|c|}{ VIAS } \\
\hline \multirow[t]{2}{*}{ Largura } & Exigida & $>=6,00$ \\
\hline & Prevista/Existente & livre \\
\hline \multirow[t]{2}{*}{ Altura livre } & Exigida & $4,50 \mathrm{~m}$ \\
\hline & Prevista/Existente & livre \\
\hline \multirow[t]{2}{*}{ Capacidade de suporte } & Exigida & $25.000 \mathrm{~kg} / 2$ eixo \\
\hline & Prevista/Existente & $25.000 \mathrm{~kg} 2$ eixo \\
\hline Tipo de contorno & \multicolumn{2}{|c|}{ livre } \\
\hline \multicolumn{3}{|c|}{ PORTÕES } \\
\hline \multirow[t]{2}{*}{ Largura } & Exigida & 4,50 \\
\hline & Prevista/Existente & 4,50 \\
\hline \multirow[t]{2}{*}{ Altura } & Exigida & 4,50 \\
\hline & Prevista/Existente & 6,00 \\
\hline
\end{tabular}

É importante salientar que todo o acesso é pavimentado e a largura é livre, ou seja, há condições de manobra em todo o espaço aberto.
Segurança estrutural contra incêndio

O objetivo de se projetar a segurança estrutural é fornecer elementos para $\mathrm{o}$ 
conjunto estrutural de uma edificação de modo que a mesma, em contato com o fogo, suporte um determinado tempo para que seja possível o retardamento da propagação das chamas e do colapso (Rodrigues, 2015).
Esta medida de segurança foi dimensionada atendendo à $\mathrm{IT} \mathrm{n}^{\circ} 08$ do Corpo de Bombeiros da Polícia Militar do Estado de São Paulo, adotada pela Portaria $\mathrm{n}^{\circ} \quad$ 001/DSCIP/CBMMT/2011. As especificações estruturais da edificação são apresentadas no quadro 3.

Quadro 3 - Características estruturais da edificação.

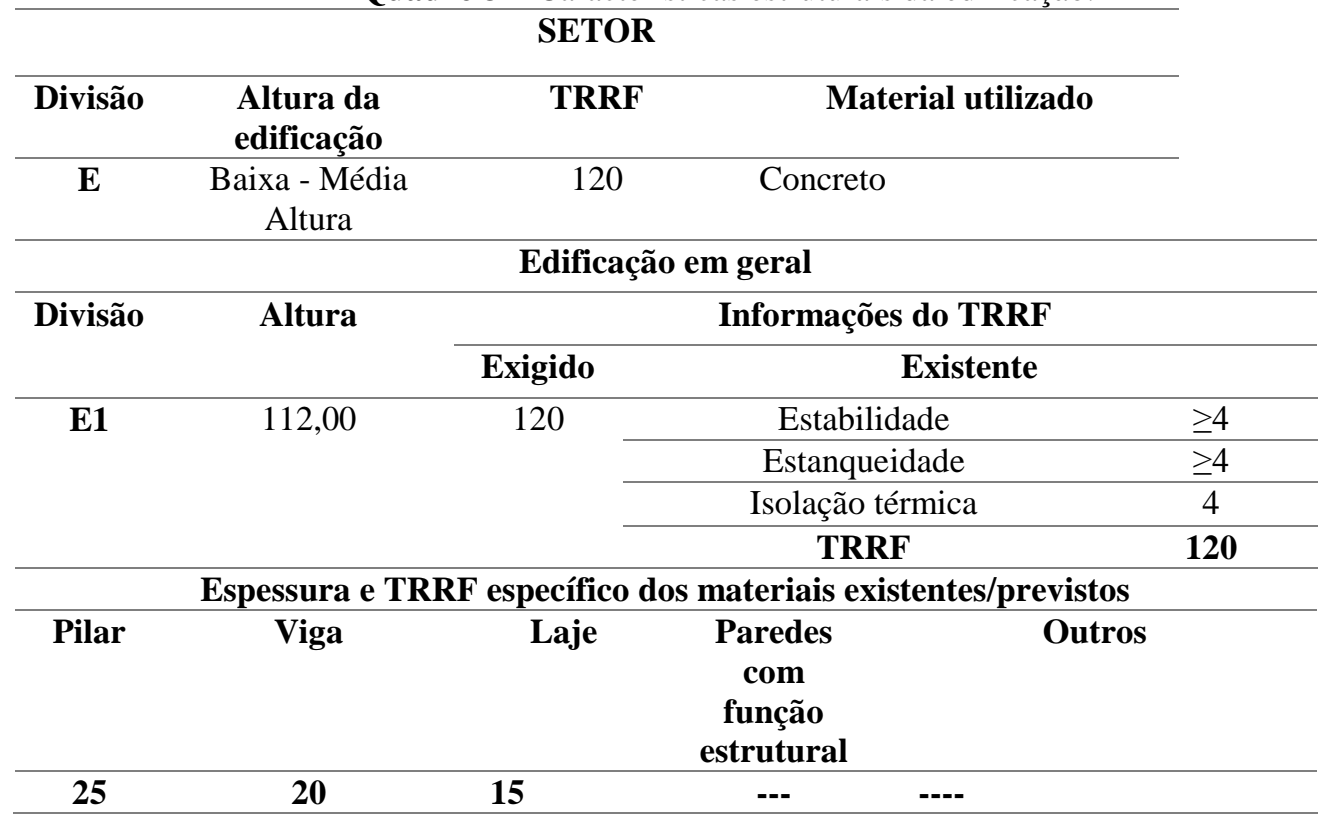

Controle de materiais de acabamento e de revestimento

Esta medida de segurança foi dimensionada atendendo a IT N. 10 do Corpo de Bombeiros da Polícia Militar do
Estado de São Paulo e adotada pela Portaria N. 001/DSCIP/CBMMT/2011. O Quadro 4 apresenta uma breve descrição das características dos materiais empregados.

Quadro 4 - Controle de materiais de acabamento e de revestimento.

\begin{tabular}{|c|c|c|c|}
\hline \multirow{2}{*}{$\begin{array}{l}\text { Grupo/ } \\
\text { Divisão }\end{array}$} & \multicolumn{3}{|c|}{ FINALIDADE DO MATERIAL } \\
\hline & Piso & $\begin{array}{l}\text { Paredes e } \\
\text { divisórias }\end{array}$ & Teto e forro \\
\hline E-1 & $\begin{array}{c}\text { Classe I, II-A, III-A ou } \\
\text { IV-A }\end{array}$ & Classe I ou II-A & $\begin{array}{l}\text { Classe I ou } \\
\text { II-A }\end{array}$ \\
\hline \multicolumn{4}{|c|}{$\begin{array}{c}\text { DESCREVER O MATERIAL UTILIZADO } \\
\text { (Previsto/Existente) }\end{array}$} \\
\hline & Piso & $\begin{array}{l}\text { Paredes e } \\
\text { divisórias }\end{array}$ & Teto e forro \\
\hline & Classe I & Classe II-A & Classe I \\
\hline
\end{tabular}


Saídas de emergência

A verificação das saídas de emergência foi realizada conforme critérios da NTCB 13/2013, e tem como princípio permitir a evacuação rápida e segura da área sobre risco. Nos Quadros 5 e 6 são apresentam os principais dados referentes às saídas de emergência.

Quadro 5 -Elementos necessários ao dimensionamento das saídas de emergência da edificação.

\section{EDIFICAÇÃO/SETOR}

\begin{tabular}{|c|c|c|}
\hline \multicolumn{2}{|r|}{ Divisão } & E-1 \\
\hline \multicolumn{2}{|r|}{ Altura } & $0,20 \mathrm{~m}$ \\
\hline \multirow[t]{3}{*}{ Tabela 1} & $\alpha$ & $\mathrm{O}$ \\
\hline & $\beta$ & Q \\
\hline & $\gamma$ & $\mathrm{U}$ \\
\hline \multicolumn{2}{|r|}{ Tabela 2} & $\mathrm{Z}$ \\
\hline \multirow[t]{4}{*}{ Tabela 3} & Acesso e descarga & 100 \\
\hline & Escadas e rampas & 60 \\
\hline & Portas & 100 \\
\hline & População & 1,50 pessoa por $\mathrm{m}^{2}$ \\
\hline \multirow[t]{2}{*}{ Tabela 4} & Exigida & $40 \mathrm{~m}$ \\
\hline & Existente & $30 \mathrm{~m}$ \\
\hline \multirow[t]{3}{*}{ Tabela 5} & Exigida & $2 \mathrm{NE}^{*}$ \\
\hline & Existente & $12 \mathrm{NE}^{*}$ \\
\hline & Tipo de Escada & NE* \\
\hline
\end{tabular}

\section{*NE - não enclausuradas}

Quadro 6 - Número de unidades de passagem segundo população e capacidade das unidades de passagem.

\begin{tabular}{|c|c|c|c|c|c|c|c|c|}
\hline \multirow[t]{2}{*}{$\begin{array}{l}\text { Discriminação do } \\
\text { pavimento/setor }\end{array}$} & \multirow[t]{2}{*}{$\begin{array}{l}\text { Ocupa- } \\
\text { ção }\end{array}$} & \multirow{2}{*}{\multicolumn{2}{|c|}{ Área $\left(\mathbf{m}^{2}\right)$}} & \multirow{2}{*}{$\begin{array}{c}\text { População Por } \\
\text { Ârea } \\
\text { Construída }\end{array}$} & \multirow{2}{*}{$\begin{array}{l}\text { Área de } \\
\text { salas de } \\
\text { aulas }\end{array}$} & \multirow{2}{*}{$\begin{array}{l}\text { Qtde de } \\
\text { pessoas } \\
\text { p/bloco }\end{array}$} & \multicolumn{2}{|c|}{$\begin{array}{l}\text { QTDE DE UNDADES DE } \\
\text { PASSAGEM }\end{array}$} \\
\hline & & & & & & & EXIGIDO & EXISTENTE \\
\hline \multirow[t]{2}{*}{ BLOCO A } & \multirow[t]{2}{*}{ D-1 } & T. & $1.843,09$ & \multirow[t]{2}{*}{$\begin{array}{l}1 \text { pessoas para } \\
\text { cada } 7,0 \mathrm{~m}^{2}\end{array}$} & --- & 264 & $3=1,65 \mathrm{~m}$ & $\begin{array}{c}2 \text { aberturas de } 3,43 \\
m+03 \text { porta de } \\
1,90 \mathrm{~m}=12,56 \mathrm{~m}\end{array}$ \\
\hline & & $1^{\circ}$ & $1.455,92$ & & ----- & 208 & $4=2,20 \mathrm{~m}$ & $\begin{array}{l}2 \text { saídas de } 2,10 \mathrm{~m} \\
\quad=4,20 \mathrm{~m}\end{array}$ \\
\hline BLOCO B & E-1 & $\mathrm{T}$ & 641,39 & $\begin{array}{l}1,5 \text { pessoas } / \mathrm{m}^{2} \\
\text { de sala de aula }\end{array}$ & 276,21 & 415 & $5=2,75 \mathrm{~m}$ & $\begin{array}{c}2 \text { aberturas de } 3,85 \\
\text { m }+04 \text { porta de } \\
0,80 \mathrm{~m}=10,90 \mathrm{~m}\end{array}$ \\
\hline BLOCO C & E-1 & $\mathrm{T}$ & $2.339,33$ & $\begin{array}{l}1,5 \text { pessoas } / \mathrm{m}^{2} \\
\text { de sala de aula }\end{array}$ & 1358,91 & 2039 & $\begin{array}{c}21=11,55 \\
m\end{array}$ & $\begin{array}{c}2 \text { aberturas de } 3,85 \\
\mathrm{~m}+01 \text { porta de } \\
1,17 \mathrm{~m}+1 \text { porta de } \\
2,97 \mathrm{~m}=11,84 \mathrm{~m}\end{array}$ \\
\hline \multirow[t]{2}{*}{ BLOCO D } & E-1 & $\mathrm{T}$ & $1.699,51$ & \multirow[t]{2}{*}{$\begin{array}{l}1,5 \text { pessoas } / \mathrm{m}^{2} \\
\text { de sala de aula }\end{array}$} & 987,30 & 1481 & $\begin{array}{c}15= \\
8,25 \mathrm{~m}\end{array}$ & $\begin{array}{l}\text { Salas dando para } \\
\text { um corredor } \\
\text { externo aberto }\end{array}$ \\
\hline & & $1^{\circ}$ & $1.306,91$ & & 677,92 & 1017 & $11=6,05 \mathrm{~m}$ & $\begin{array}{l}2 \text { aberturas de } 3,85 \\
m=7,70 m\end{array}$ \\
\hline $\begin{array}{l}\text { ALMOXERIFAD } \\
\text { O }\end{array}$ & D-1 & & $1.000,00$ & $\begin{array}{l}1 \text { pessoas para } \\
\text { cada } 7,0 \mathrm{~m}^{2}\end{array}$ & ----- & 143 & $2=1,10 \mathrm{~m}$ & 01 porta de $1,20 \mathrm{~m}$ \\
\hline \multirow[t]{2}{*}{ BLOCO E } & \multirow[t]{2}{*}{ E-1 } & $\mathrm{T}$ & $1.154,47$ & \multirow[t]{2}{*}{$\begin{array}{l}1,5 \text { pessoas } / \mathrm{m}^{2} \\
\text { de sala de aula }\end{array}$} & 607,08 & 911 & $9=4,95 \mathrm{~m}$ & $\begin{array}{c}3 \text { aberturas de } 3,85 \\
\mathrm{~m}+01 \text { porta } \\
1,17 \mathrm{~m}=12,72 \mathrm{~m}\end{array}$ \\
\hline & & $1^{\circ}$ & $1.151,87$ & & 464,77 & 698 & $7=3,85 \mathrm{~m}$ & 2 aberturas de 3,85 \\
\hline
\end{tabular}


Dias A. C. de O.; Marchetto M. Processo de Segurança Contra Incêndio e Pânico no Complexo da FAET/ICET/IF, UFMT - Campus Cuiabá. E\&S - Engineering and Science, (2016), 5:2.

\begin{tabular}{|c|c|c|c|c|c|c|c|c|}
\hline & & & & & & & & $\mathrm{m}=7,70 \mathrm{~m}$ \\
\hline \multirow[t]{4}{*}{ BLOCO F } & \multirow[t]{4}{*}{ E-1 } & $\mathrm{T}$ & $1.906,13$ & \multirow[t]{4}{*}{$\begin{array}{l}1,5 \text { pessoas } / \mathrm{m}^{2} \\
\text { de sala de aula }\end{array}$} & 863,01 & 1295 & $13=7,15 \mathrm{~m}$ & $\begin{array}{c}3 \text { aberturas de } 3,85 \\
m=11,55 m\end{array}$ \\
\hline & & $1^{\circ}$ & $1.889,88$ & & 438,70 & 659 & $7=3,85 \mathrm{~m}$ & $\begin{array}{c}\text { 01 esc. } 3,70 \mathrm{~m}+1 \\
\text { esc. } 2,10+2 \text { esc. } \\
1,90=9,58 \mathrm{~m}\end{array}$ \\
\hline & & $2^{\circ}$ & $2.011,27$ & & 675,35 & 1014 & $\begin{array}{c}17= \\
9,35 \mathrm{~m}\end{array}$ & $\begin{array}{c}01 \text { esc. } 3,70 \mathrm{~m}+1 \\
\text { esc. } 2,10+2 \text { esc. } \\
1,90=9,58 \mathrm{~m}\end{array}$ \\
\hline & & $3^{\circ}$ & 182,89 & & 72,43 & 110 & $2=1,10 \mathrm{~m}$ & $\begin{array}{l}\text { 01 escada 2,10 m } \\
\text { de largura }\end{array}$ \\
\hline
\end{tabular}

É importante esclarecer que devido a este estudo de saídas de emergências da referida edificação, constatou-se que devese construir mais duas saídas, sendo uma no bloco D e outra no $\mathrm{E}$, compostas por perfis metálicos e não enclausuradas, alternativas estás por ser mais econômicas e rápidas para a atual situação que a edificação.

\section{Plano de intervenção de incêndio}

O Plano de Intervenção de Incêndio foi elaborado conforme às exigências da IT $\mathrm{n}^{\circ} 16$ do Corpo de Bombeiros da Polícia Militar do Estado de São Paulo, adotada pela Portaria $\mathrm{n}^{\circ}$ 001/DSCIP/CBMMT/2011. No qual aborda todos os aspectos para que o Corpo de Bombeiros intervenha no interior da edificação com todas as informações possíveis referentes aos riscos presentes. Além disso, esses dados podem ser utilizados pelo próprio ocupante da edificação

De forma genérica o Plano de Intervenção é um resumo de todas as informações para que seja manuseado facilmente na hora do acidentem como apresenta no Quadro 7.

Tendo como base uma intervenção imediatista, que será realizada por recurso humano presente no campus, é importante esclarecer que seria interessante que a instituição como um todo, fosse protegida por uma equipe terceirizada de Bombeiros Civis. Sendo uma opção econômica e viável, no qual se ganha mais um tempo de resposta aceitável para algum possível sinistro.

Sobre a capacidade do reservatório, sabe-se que segundo o Pró-reitoria de Planejamento a UFMT será atendida por uma rede geral com reservatório também geral.

Quadro 7 - Informações básicas para o Plano de intervenções de Incêndio

\begin{tabular}{|c|c|}
\hline Horário de funcionamento & 7:00 AS 22:00 hs \\
\hline \multirow{3}{*}{ População } & Fixa \\
\hline & Flutuante \\
\hline & PNE \\
\hline \multicolumn{2}{|c|}{ Existem pontos fixos para ancoragem de cordas? } \\
\hline \multicolumn{2}{|c|}{ Sistemas de combate a incêndio } \\
\hline Possui hidrante & $(\mathrm{x}) \operatorname{Sim}$ \\
\hline \multicolumn{2}{|c|}{ Capacidade do reservatório de água } \\
\hline \multicolumn{2}{|c|}{ Apoio externo } \\
\hline Corpo de Bombeiros & 193 \\
\hline Endereço & Av. Fernando Corrêa da Costa, s/n. \\
\hline Distância & $4,3 \mathrm{Km}$ \\
\hline Tempo resposta & 6 minutos (sem transito) \\
\hline SAMU & 192 \\
\hline Endereço & Rua Oriente Tenuta, 58 - Senhor dos Passos \\
\hline Distância & $7,7 \mathrm{Km}$ \\
\hline Tempo resposta & 15 minutos (sem transito) \\
\hline
\end{tabular}




\begin{tabular}{ll}
\hline \multicolumn{1}{c}{ Polícia Militar } & \multicolumn{1}{c}{190} \\
\hline Endereço & Rua Montevieo - Jardim das Américas \\
\hline Distância & $1,8 \mathrm{~km}$ \\
\hline Tempo resposta & $\mathbf{2 2}$ minutos (sem transito) \\
\hline
\end{tabular}

\section{Brigada de incêndio}

Quando se trata de brigada, deve-se levar em conta que o tempo-resposta das equipes de emergência não seria suficiente para que as mesmas debelassem as chamas ou evacuassem as pessoas do local sinistrado.

Portanto possuir um amparo especializado dentro da instituição faz com que a comunidade fica tenha mais segurança diante de uma situação de risco.

Diante desses motivos, é de suma importância que a UFMT, como um todo, deverá ser protegida por uma equipe especializada de Bombeiros Civis, os quais serão distribuídos em setores estrategicamente estudados, para que se tenha um tempo de resposta aceitável, mas é claro levando em conta a toda a adversidade da dispersão setorial que compõem o campus.
Porém como este tipo de estudo não é objeto deste artigo, não será aprofundado este tema, pois sabe-se que trata de um problema macro da Instituição e não somente do complexo estudado.

\section{Iluminação de emergência}

A iluminação de emergência é dentre os itens de segurança, o mais funcional. Pois, é ela que direciona a saída segura para o espaço livre exterior e fornece condições de resgate e manobras emergenciais às equipes de socorro. Enquanto as pessoas não se aterem a ideia de que os preventivos da edificação são para serem utilizadas por elas mesmas, a saída imediata será a única solução (Rodrigues, 2015).

Esta medida de segurança foi dimensionada conforme a NBR 10.898, normativa adotada pela Portaria N. 001/DSCIP/CBMMT/2011. Segundo o Quadro 8 abaixo, no qual apresenta as principais características do sistema de iluminação de emergência.

Quadro 8 - Características do sistema de iluminação de emergência por blocos autônomos.

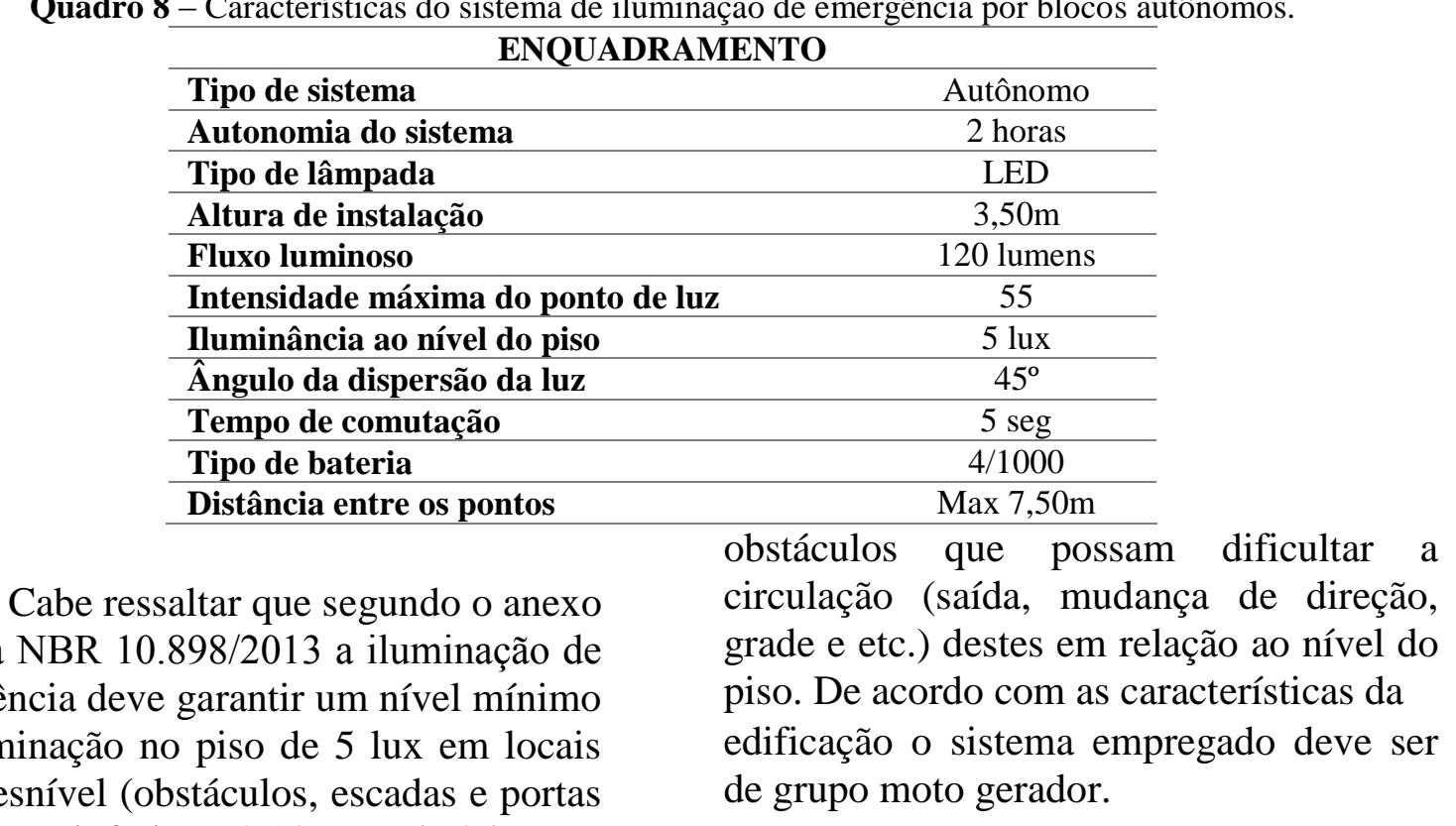
com altura inferior a 2,10 m) e de 3 lux em locais planos (corredores e Halls). Além disso, deve permitir o reconhecimento de 


\section{Sistema de detecção e alarme de incêndio}

Esta medida de segurança foi dimensionada atendendo à NBR 17.240, adotada pela Portaria N. 001/DSCIP/CBMMT/2011. As especificidades do sistema de alarme de incêndio são exibidas no Quadro 9.

O sistema de detecção de incêndio consiste em um conjunto de elementos planejadamente dispostos e adequadamente interligados a fim de que possa fornecer informações de princípios de incêndio, por meio de indicações sonoras e/ou visuais.

O sistema de alarme de incêndio consiste em um conjunto de elementos dispostos e adequadamente interligados a fim de que possa fornecer informações de princípios de incêndio, por meio de indicações sonoras e/ou visuais, através do alarme.

Quadro 9 - Características do sistema de alarme de incêndio.

\begin{tabular}{|c|c|c|}
\hline \multicolumn{3}{|c|}{ Acionadores } \\
\hline \multirow[t]{2}{*}{ Altura de instalação } & Exigida & 1,60 \\
\hline & Prevista/Existente & 1,40 \\
\hline \multirow{2}{*}{$\begin{array}{c}\text { Distância máxima a ser } \\
\text { percorrida }\end{array}$} & Exigida & 15,00 \\
\hline & Prevista/Existente & 15,00 \\
\hline \multicolumn{3}{|c|}{ Avisadores Sonoros } \\
\hline \multirow{2}{*}{$\begin{array}{l}\text { Nível médio do som do } \\
\text { ambiente }\end{array}$} & Exigido & $50 \mathrm{~dB}$ \\
\hline & Previsto/Existente & $50 \mathrm{~dB}$ \\
\hline \multirow[t]{2}{*}{ Potência sonora } & Exigida & $60 \mathrm{~dB}$ \\
\hline & Prevista/Existente & $60 \mathrm{~dB}$ \\
\hline
\end{tabular}

Ambos serão controlados por dispositivos de segurança e de combate automático quando instalados na edificação, por onde todo o bloco será supervisionado.

Cabe ressaltar que na sala de controle localizada no escritório, onde terá uma Central de Alarme, do tipo endereçável, capaz de reconhecer de reconhecer individualmente cada acionador manual

A partir desta central deriva duas redes de tubulação, a primeira em ferro galvanizado, interliga os pontos de detecção e acionadores e a segunda em PVC rígido, alimenta os pontos de alarme de incêndio, conforme as plantas do projeto.

Acionador Manual: Próximo a cada hidrante e em locais estratégicos, foram previstos acionadores manuais, tipo "QUEBRA VIDRO”, apropriada para sistema endereçável.

Indicador Sonoro/Visual: A sinalização sonora/visual será única, sendo que a instalação de sirene deverá ser incorporada na central de Alarme de Incêndio na sala de Controle.

- As Sirenes Eletrônicas deverão obedecer às seguintes especificações:

- Do tipo eletrônico, som ondulante;

- Tensão de operação: 24 VCC;

- Potência: $2 \mathrm{~W}$;

- Alto-falante do tipo "TWEETER". Com intensidade mínima de $60 \mathrm{~dB}$.

\section{Sinalização de emergência}

Esta medida de segurança foi dimensionada atendendo à NBR 13.434/2013, adotada pela Portaria N. 001/DSCIP/CBMMT/2011. Sendo que por norma a sinalização possui três objetivos:

- Reduzir a ocorrência de incêndio ou acidentes;

- Garantir as ações para o controle e/ou extinção do risco; e,

- Definir as rotas para o abandono seguro das edificações. 
Dias A. C. de O.; Marchetto M. Processo de Segurança Contra Incêndio e Pânico no Complexo da FAET/ICET/IF, UFMT - Campus Cuiabá. E\&S - Engineering and Science, (2016), 5:2.

As especificidades das sinalizações de quadros 10 e 11. emergência são apresentadas pelos

Quadro 10 - Características das sinalizações de emergência, segundo finalidade, forma e cores.

\begin{tabular}{cccc}
\hline \multicolumn{4}{c}{ Sinalização (Básica e/ou Complementar) } \\
\hline Tipo & Forma & Cor do fundo & Cor do símbolo \\
\hline $\begin{array}{c}\text { Orientação/socorro } \\
\begin{array}{c}\text { Equipamentos de combate a } \\
\text { incêndio }\end{array}\end{array}$ & Quadrada/retangular & verde & fotoluminescente \\
\hline
\end{tabular}

Quadro 11 - Dimensões das placas de sinalização.

\begin{tabular}{cccccc}
\hline & \multicolumn{3}{c}{ Dimensões } \\
\hline $\begin{array}{c}\text { Distância de } \\
\text { visualização }(\mathbf{m})\end{array}$ & $\begin{array}{c}\text { Lado, altura ou } \\
\text { diâmetro }(\mathbf{m})\end{array}$ & $\begin{array}{c}\text { Área da } \\
\text { placa }\left(\mathbf{m}^{2}\right)\end{array}$ & $\begin{array}{c}\text { Altura das } \\
\text { letras }(\mathbf{m})\end{array}$ & $\begin{array}{c}\text { Altura de instalação } \\
(\mathbf{m})\end{array}$ & $\begin{array}{c}\text { Exigida } \\
\text { Prevista }\end{array}$ \\
\hline $\mathbf{6 , 0 0 m}$ & $0,25 \times 0,10$ & 0,025 & 0,05 & 3,00 & $2,20 \mathrm{~m}$ \\
\hline
\end{tabular}

Para rotas de saída a sinalização de orientação deverá localizar-se à distância máxima de 7,5 m da porta de saída de emergência, com distância máxima entre si de $15 \mathrm{~m}$ e sua base deverá estar a no mínimo 1,80 $\mathrm{m}$ do piso acabado. As placas sinalizando os extintores deverão ser instaladas a uma altura máxima de $1,80 \mathrm{~m}$, medida do piso acabado à base da sinalização.

Sobre as portas, deverão ser instaladas placas de sinalização, indicando as saídas.

A cor vermelha deverá ser utilizada para distinguir equipamentos e aparelhos de proteção e combate a incêndios. Sendo empregado para identificar:

- Caixa de Alarme de Incêndio;

- Hidrantes;

- Extintores e sua localização;

- Tubulações, válvulas e registros de água para incêndio; e
- Em botões interruptores de circuitos elétricos para paradas de emergência.

\section{Extintores}

Não têm como negar que os extintores são os melhores aliados para o combate aos princípios de incêndio. É claro que se solicita atenção para o fato dele serem utilizados somente nos princípios de incêndio, pois a sua pequena carga, demanda um tempo muito curto de combate.

Esta medida de segurança foi dimensionada atendendo ao Decreto Estadual N. 857/1984 do Estado de Mato Grosso. O Quadro 12 expõe as principais características do sistema de proteção por extintores manuais. 
Dias A. C. de O.; Marchetto M. Processo de Segurança Contra Incêndio e Pânico no Complexo da FAET/ICET/IF, UFMT - Campus Cuiabá. E\&S - Engineering and Science, (2016), 5:2.

Quadro 12 - Propriedades do sistema de proteção por extintores manuais de incêndio.

\begin{tabular}{cccccc}
\hline Tipo & & PQS & $\mathbf{H}_{2} \mathbf{O}$ & $\mathbf{C O}_{2}$ & $\mathbf{A B C}$ \\
\hline Peso (kg ou L) & & $4 \mathrm{~kg}$ & 101 & $6 \mathrm{~kg}$ & $6 \mathrm{Kg}$ \\
\hline Capacidade extintora & & $10 \mathrm{~B}$ & $2 \mathrm{~A}$ & $2 \mathrm{~B}$ & \\
\hline Distância máxima a percorrer & Exigido & 30 & 30 & 30 & 30 \\
& & & & & \\
\cline { 2 - 6 } & Previsto & 25 & 25 & 25 & 30 \\
\hline Área de cobertura & & 500 & 500 & 500 & 500 \\
\hline Altura de instalação & Exigido & 1,80 & 1.80 & 1.80 & 1.80 \\
\cline { 2 - 6 } & Previsto & 1.60 & 1.60 & 1.60 & 1.60
\end{tabular}

Cabe informar o sistema de extintores portáteis foi projetado para proteger os riscos da edificação de modo que a quantidade, os tipos e capacidades dos extintores estão em função:

- da natureza do fogo;

- do agente extintor;

- da quantidade do agente extintor; e
- da distância máxima a ser percorrida.

\section{Hidrantes}

Esta medida de segurança foi dimensionada atendendo à NTCB 19/2015 do Corpo de Bombeiros Militar do Estado de Mato Grosso. O Quadro 13 apresenta as características do sistema de hidrantes da edificação.

Quadro 13 - Características do sistema de hidrantes

\begin{tabular}{|c|c|c|c|}
\hline \multicolumn{2}{|c|}{ Reservatório } & \multirow{2}{*}{\multicolumn{2}{|c|}{ Acionamento do sistema }} \\
\hline Posição & Material & & \\
\hline APOIADO & $\mathrm{AÇO}$ & \multicolumn{2}{|c|}{ BOTOEIRA } \\
\hline \multicolumn{2}{|c|}{ Esguicho } & \multicolumn{2}{|c|}{ Mangueira } \\
\hline Tipo & $\begin{array}{c}\text { Diâ } \\
\text { metroo }\end{array}$ & Metragem & Diâmetro \\
\hline $13 \mathrm{~mm}$ & $38 \mathrm{~mm}$ & $30 \mathrm{~m}$ & $38 \mathrm{~mm}$ \\
\hline
\end{tabular}

Continua Quadro 14 - Características do sistema de hidrantes

- Hidrantes

\begin{tabular}{cccc}
\hline Instalados & Desfavoráveis & Pressão por hidrante & Vazão por hidrante \\
\hline H1 & 15.00 & $4.77 \mathrm{l} / \mathrm{s}$ \\
\hline H2 & 19.86 & $5.49 \mathrm{l} / \mathrm{s}$ \\
\hline H3 & 28.98 & $4.70 \mathrm{l} / \mathrm{s}$ \\
\hline H4 & 29.46 & $4.74 \mathrm{l} / \mathrm{s}$ \\
\hline
\end{tabular}

Gás liquefeito de petróleo

A central de GLP foi dimensionada atendendo à NBR 13523, adotada pela
Portaria $\mathrm{n}^{\circ}$ 001/DSCIP/CBMMT/2011 e detalhada no Quadro 14. 
Quadro 15 - Características da Central de GLP.

\begin{tabular}{|c|c|c|c|}
\hline \multicolumn{4}{|c|}{ CENTRAL } \\
\hline \multicolumn{3}{|c|}{ Quantidade de recipientes } & 6 \\
\hline \multicolumn{3}{|c|}{ Capacidade volumétrica individual } & 90 \\
\hline \multicolumn{3}{|c|}{ Capacidade volumétrica total } & 540 \\
\hline \multirow[t]{5}{*}{ Classificação } & Localizaç & & Casa de gás \\
\hline & Formato & & Cilíndrico \\
\hline & Posição & & Vertical \\
\hline & Fixação & & Apoiado \\
\hline & Abastecin & & Por botijões \\
\hline \multicolumn{4}{|c|}{ Área de superfície externa } \\
\hline \multirow{9}{*}{$\begin{array}{l}\text { Distâncias } \\
\text { (recipientes) }\end{array}$} & Divisa de & riedades & 50,00 \\
\hline & Entre reci & & 0,30 \\
\hline & $\begin{array}{l}\text { Aberturas } \\
\text { válvula d }\end{array}$ & $\begin{array}{l}\text { Ixo da descarga da } \\
\text { urança }\end{array}$ & $10 \mathrm{~cm}$ \\
\hline & Fontes de & ร̃o & Protegido \\
\hline & Portas e $\mathrm{j}$ & & 3,00 \\
\hline & $\begin{array}{l}\text { Produtos } \\
\text { inflamáve }\end{array}$ & $\begin{array}{l}\text { xicos, perigosos, } \\
\text { hama aberta }\end{array}$ & 60,00 \\
\hline & Materiais & bustíveis & 150,00 \\
\hline & Redes & Nível de tensão & $220 / 380 \mathrm{~V}$ \\
\hline & elétricas & Distância & 200,00 \\
\hline \multirow[t]{4}{*}{ Parede } & Tempo de & stência & $60 \mathrm{~min}$ \\
\hline & Altura & & $2,20 \mathrm{~m}$ \\
\hline & Distância & cipiente & $0,50 \mathrm{~m}$ \\
\hline & Comprim & & $3,00 \mathrm{~m}$ \\
\hline \multicolumn{3}{|c|}{ Distância da central com cerca de proteção } & 1500 \\
\hline \multicolumn{3}{|c|}{ Quantidade e capacidade dos extintores } & Tipo ABC - 2x6 kg \\
\hline
\end{tabular}

\section{CONCLUSÃO}

Diante tudo exposto sabe-se que o complexo estudado foi classificado como E-1, segundo a Lei 8399/2005, a qual informa que os preventivos que devem estar presentes no local são relacionados, a seguir:

- Acesso de viatura a edificação;

- Segurança estrutural contra Incêndio;

- Controle de materiais de acabamento;

- Saída de emergência;

- Plano de intervenção de incêndio;

- Brigada de incêndio;

- Iluminação de emergência;

- Alarme de incêndio;

- Detecção de incêndio;

- Sinalização de emergência;

- Extintores;

- Hidrantes.
Diante visitas in loco, não se pode negar que a edificação estudada possui uma construção antiga com um sistema de prevenção e combate incêndio e pânico deficiente, defasado e insuficiente quanto às necessidades normativas, que não contribuirá de forma eficaz, no caso de ocorrência de sinistros, para o alerta e evacuação da população da edificação, para o combate ao fogo e para a preservação do patrimônio existente.

Em análise minuciosa constatou-se que o prédio não possui saídas de emergência em número suficiente em caso de sinistro, não possui brigada de incêndio, os quais são imprescindíveis para a primeira resposta ao fogo em caso de sinistro, até a chegada do Corpo de Bombeiros. Não se encontra in loco medidas preventivas relacionadas a alarme e detecção de fumaça, nem sinalização e iluminação de emergência, que é de suma 
importância em caso de sinistro. Faz-se necessário que haja placas de indicação e iluminação de emergência para a desocupação do prédio com celeridade e livre de pânico, o que não seria possível no local pelas condições existentes. Os extintores não estão dispostos corretamente, não possui quantidade suficiente de extintores portáteis de água pressurizada, e não há sinalização de indicação, ou seja, este preventivo não atende ao Decreto 857/1984. Os hidrantes não se encontram instalados a $5 \mathrm{~m}$ de porta e escadas conforme preconiza a legislação vigente, estão obstruídos além de a reserva técnica de incêndio não atender o sistema durante o tempo mínimo de funcionamento, logo, o sistema de hidrantes existente não atende ao Decreto $857 / 1984$.

\section{RECOMENDAÇÕES}

Com caráter de sugestão recomenda-se alguns itens que são importantes para minimizar os riscos aos ocupantes de uma edificação, são eles:

- Compor equipe especializada de Bombeiros Civis para a formação da brigada de incêndio bem treinada e atuante, distribuídos em setores estrategicamente no campus;

- Construir saídas de emergências conforme preconiza norma, em tamanho e número suficiente;

- Conhecer o comportamento das pessoas da edificação para o direcionamento do abandono da edificação em caso de incêndio, com segurança e tranquilidade;

- Executar os sistemas propostos: de detecção de alarme, iluminação, sinalização, hidrante e extintores de incêndio.

\section{REFERÊNCIAS}

ABNT. ASSOCIAÇÃO BRASILEIRA DE NORMAS TÉCNICAS. NBR 9077: Saída de emergência em edifícios. Rio de Janeiro, 2001.

ABNT. ASSOCIAÇÃO BRASILEIRA DE NORMAS TÉCNICAS. NBR 1389:

Glossário de termos relacionados à segurança contra incêndio. Rio de Janeiro, 1997.

ABNT. ASSOCIAÇÃO BRASILEIRA DE NORMAS TÉCNICAS. NBR 10898: Sistemas de iluminação de emergência. Rio de Janeiro, 1999.

ABNT. ASSOCIAÇÃO BRASILEIRA DE NORMAS TÉCNICAS. NBR 12693: Sistemas de proteção por extintores de incêndio. Rio de Janeiro, 1993.

ABNT. ASSOCIAÇÃO BRASILEIRA DE NORMAS TÉCNICAS. NBR 134341: Sinalização de segurança contra incêndio e pânico. Parte 1: princípios de projeto. Rio de Janeiro, 2004.

ABNT. ASSOCIAÇÃO BRASILEIRA DE NORMAS TÉCNICAS. NBR 134342: Sinalização de segurança contra incêndio e pânico. Parte 2: símbolos e suas fomas, dimensões e cores. Rio de Janeiro, 2004.

ABNT. ASSOCIAÇÃO BRASILEIRA DE NORMAS TÉCNICAS. NBR 13714: Sistema de hidrantes e de mangotinhos para combate a incêndio. Rio de Janeiro, 2000.

ABNT. ASSOCIAÇÃO BRASILEIRA DE NORMAS TÉCNICAS. NBR 14276: Brigada de incêndio - requisitos. Rio de Janeiro, 2006.

ABNT. ASSOCIAÇÃO BRASILEIRA DE NORMAS TÉCNICAS. NBR 17240: Sistema de detecção e alarme de incêndio - projeto, instalação, comissionamento e manutenção de sistema de detecção e alarme - requisitos. Rio de Janeiro, 2010.

BRENTANO, T. A proteção contra incêndios no projeto de edificações. Porto

Alegre: Gráfica Calábria, 2007. 
CAMILO, Abel B. Manual de Prevenção e Combate a Incêndio. 11. ed. São Paulo: SENAC, 2011.

FAGUNDES, F. Plano de prevenção e combate a incêndios: estudo de Caso em edificação residencial multipavimentada. $2013 . \quad 71 \mathrm{f}$. Monografia Pós Graduação Lato Sensu Engenharia de Segurança do Universidade Regional do Noroeste do Estado do Rio Grande do Sul, Santa Rosa, 2013.

MARCHETTO, M. Editorial, Scientific Journal Eng. And Science, 2014, 1:1

MATO Grosso (Estado). Decreto n. 857, de 29 de agosto de 1984. Dispõe sobre especificação para instalação de proteção contra incêndio.

MATO Grosso (Estado). Lei n. 8399, de 22 de dezembro de 2005. Dispõe sobre lei de segurança contra incêndio e pânico de Mato Grosso.

MATO Grosso (Estado). Norma Técnica do Corpo de Bombeiros $\mathrm{N}^{\circ} 01 / 2008$. Procedimentos administrativos.

MATO Grosso (Estado). Portaria n. 0001, de 12 de maio de 2011. Dispõe sobre adoção normas técnicas para padronização dos serviços de segurança contra incêndio e pânico no âmbito do CBM/MT. Diário oficial, Cuiabá, p. 22, 12 maio 2001.

MELO, Eduardo. A. L. Curso de Instalações prediais de proteção contra incêndio. FINATEC. Brasília, DF, 1999. MORAES, Jerté Z. Projeto de Prevenção e Combate a Incêndio na Indústria
Química. Dissertação (Especializaçãoem Engenharia de Segurança do Trabalho), Pós-graduação, Universidade do extremo Sul Catarinense, Criciúma, 2012. RODRIGUES, E. F., 2015. Manual para Análise de Processo de segurança contra Incêndio e Pânico. Cuiabá: Corpo de Bombeiro Militar de Mato Grosso .

SÃO Paulo (Estado). Instrução Técnica. $\mathrm{N}^{\circ} 02 / 2011$. Conceitos Básicos de Segurança contra Incêndio.

SÃO Paulo (Estado). Instrução Técnica. $\mathrm{N}^{\circ} 03 / 2011$. Terminologia de Segurança contra Incêndio.

SÃO Paulo (Estado). Instrução Técnica. $\mathrm{N}^{\circ} 06 / 2011$. Acesso de Viatura na Edificação e Área de Risco.

SÃO Paulo (Estado). Instrução Técnica. $\mathrm{N}^{\circ} 08 / 2011$. Resistencia ao Fogo dos elementos de Construção.

SÃO Paulo (Estado). Instrução Técnica. $\mathrm{N}^{\circ} 10 / 2011$. Controle de Materiais de Acabamento e de Revestimento.

SÃO Paulo (Estado). Instrução Técnica. $N^{\circ} 14 / 2011$. Carga de Incêndio nas Edificações e Áreas de Risco.

SÃO Paulo (Estado). Instrução Técnica. $N^{\circ} 16 / 2011$. Plano de Emergência contra Incêndio.

SÃO Paulo (Estado). Instrução Técnica. No17/2011. Brigada de Incêndio.

SEITO, Alexandre I. Segurança Contra Incêndio no Brasil. São Paulo: Projeto Editora, 2008. 